\title{
A Qualitative Investigation into the Representations of Habit by Lay People
}

Daniel J. Brown ${ }^{1}$, Shirley Morrissey ${ }^{1}$, Martin S. Hagger ${ }^{123}$, Kyra Hamilton ${ }^{1}$

${ }^{1}$ School of Applied Psychology and Menzies Health Institute, Griffith University, BRISBANE, Australia.

${ }^{2}$ Psychological Sciences, University of California, MERCED, USA

${ }^{3}$ Faculty of Sport and Health Sciences, University of Jyväskylä, JYVÄSKYLÄ, Finland

Submitted version, 29/12/19. This paper is under preparation and may not exactly replicate the final published version. Please do not copy or cite without the author's permission.

Author contributions: Author DB contributed to the conception, design, data-collection, analysis, and writing of the manuscript; author SM contributed to the conceptualisation and writing of the manuscript; author MS contributed to the design and revisions of the manuscript; author $\mathrm{KH}$ contributed to the conception, design, analysis, and writing of the manuscript.

Funding: This research did not receive any specific grant from funding agencies in the public, commercial, or not-for-profit sectors. This project was supported by the Australian Government Research Training Program. Martin S. Hagger's contribution was supported by a Finland Distinguished Professor (FiDiPro) fellowship from Tekes, the Finnish funding agency for innovation.

Correspondence concerning this article should be addressed to Daniel Brown, Health and Psychology Innovations (HaPI) Research Lab, School of Applied Psychology, Griffith University, 176 Messines Ridge Road, Mt Gravatt, QLD 4122.

Email: daniel.brown@griffithuni.edu.au or hapiresearch@gmail.com

Word Count:

Keywords: habit; lay representations; routine 
LAY REPRESENTATIONS OF HABIT

\begin{abstract}
Objective: There is continued debate regarding the most useful and meaningful way to measure habit and how to form habits via intervention. To date, lay representations of habit have rarely been explored. Such understandings may provide clarity on how researchers might better define habit, develop valid measurements of habit, and evaluate habit-based interventions. This study aimed to explore how lay people represent habit, across two studies.
\end{abstract} Methods: Study $1(N=158)$ used an online, open-ended questionnaire to elicit what lay people believe to be the salient features of habit. Study 2 involved a series of interviews and focus groups $(N=27)$, to explore individual representations of habit. Results: Theoretical thematic content analysis across the two studies revealed that participants described habit by what it is (i.e., an explicit outcome or internal mechanism), by habit's features (i.e., automatic, frequent, stable cue/context, and emotionally rewarding), and by how they evaluated habits (i.e., being both "good" and "bad"). When describing the characteristics of habitual behaviours, participants identified that habits were either simple, discrete behaviours; clustered, repetitive behaviours synonymous with routine; or a self-identity characteristic. Conclusions: Current findings indicate that lay people hold consistent and contradictory representations of habit. Largely, lay representations were similar to scientific conceptualisations, with some notable difference. Participants appeared to misunderstand the cue-based mechanism of habits, interchangeably used 'habit' with 'routine', and believed that habits were emotionally rewarding. Future research should focus on integrating the beliefs identified in this research with new measures of habit and habit interventions. 
LAY REPRESENTATIONS OF HABIT

"Habit", as a concept, has a long history in the scientific literature (Barandiaran \& Di Paolo, 2014; James, 1891; Triandis, 1977). Definitions of habit can be identified as far back as Aristotle in the Classical period; yet, it is only more recently that researchers started to examine and define the various features of habit (see Barandiaran \& Di Paolo, 2014 for an overview). While researchers have typically agreed that habit can play a role in the initiation and enactment of behaviour (Gardner, 2015; Mullan \& Novoradovskaya, 2018; Orbell \& Verplanken, 2015; Wood \& Rünger, 2016), there remains debate on what characterises habit. To date, researchers have typically, but not always, ignored the perspective of lay people and how they understand what the term 'habit' means, how habits are formed, and how habits might be broken (Gardner, 2015; Verplanken \& Orbell, 2003; Wood \& Rünger, 2016). As a result, self-reported responses to research investigating habit and/or to evaluate interventions seeking to modify habits are fraught with problems regarding the conceptualisation and operationalisation of habit.

This paper explores how lay people represent the concept of habit. First, the paper will outline scientific definitions and conceptualisations of habit that may be drawn upon in understanding the lay representations of habit. Then it will describe how understanding the way lay people represent habit may help refine the scientific conceptualisations of habit, as well as improve habit measurement and the evaluations of habit intervention. To do this, the current investigation involved an open-ended questionnaire design (Study 1) followed by indepth interviews and focus groups (Study 2). The findings revealed that mostly lay people represent habit in similar ways to scientific conceptualisations; however, there were also some interesting differences. The findings provide further insights into lay people's understanding of habit that may help to refine future habit research.

Historically habit has been characterised from two perspectives. The first is that of a behavioural and 'associationist' perspective, whereby habits are considered to involve 


\section{LAY REPRESENTATIONS OF HABIT}

reactive automatism, unaffected by desires and cognitive processes (e.g., after a specific noise an action always ensues). The second is known as an "organiscism" trend whereby habits are part of a dynamic system; and are both cause and effect. The organicism trend suggests that habits interdepend on other internal processes which, in turn, determine the formation and maintenance of the habit (i.e., habits are the way individuals "typically" engage in the world) (Barandiaran \& Di Paolo, 2014).

In a narrative review and examination of the multiple, modern definitions of habit, Gardner (2015) found both consistencies and contradictions that likely have important implications regarding how habit is measured, modelled, and manipulated (i.e., intervened upon). For example, across current definitions of habits, inconsistencies are found with regard to identifying what a habit is. As indicated above, some definitions of habit describe it as a behaviour (i.e., "behavioural patterns, based on learned context behaviour associations"; Gardner, de Bruijn, \& Lally, 2012, p. 1; "behaviour that has been repeated until it has become more or less automatic"; Nilsen, Roback, Broström, \& Ellström, 2012, p. 1), while others describe habit as a tendency towards a behaviour (i.e., "tendencies to repeat responses given a stable supporting context"; Ouellette \& Wood, 1998, p. 55), or a type of automaticity (i.e., "A type of automaticity in responding that develops as people repeat actions in stable circumstances"; Verplanken \& Wood, 2006, p. 91; “A type of automaticity characterized by a rigid contextual cueing of behavior"; Wood \& Neal, 2009, p. 580).

More recently, researchers (e.g., Gardner, 2015) have argued that treating habit simply as a behaviour is incompatible with health behaviour models which treat habit as a determinant of behaviour (see e.g., Evans \& Stanovich, 2013; Hagger, Trost, Keech, Chan, \& Hamilton, 2017; Triandis, 1977; Wood, Quinn, \& Kashy, 2002). It has also been argued that a definition of habit that treats habit as both the behaviour and the cause of the behaviour (Gardner, 2015; Maddux, 1997), results in an incoherent, circular, and potentially unhelpful 


\section{LAY REPRESENTATIONS OF HABIT}

definition. So, while research has demonstrated that habit can predict behaviour, and habitual behaviour can be frequent, according to many researchers a habit cannot be simultaneously both a behaviour and the determinant of the same behaviour (Adriaanse, Kroese, Gillebaart, \& De Ridder, 2014; Allom et al., 2018; Brown, Hagger, \& Hamilton, 2019).

Other researchers define habit as an 'automatic behaviour' or a 'type of automaticity', which is to say habit is the act of doing something without forethought in response to a cue (Verplanken \& Wood, 2006; Wood \& Neal, 2009). Often the word 'automaticity' is used interchangeably with 'habit' and previous studies have used a scale of behavioural automaticity as a proxy of habit (Gardner, Abraham, Lally, \& de Bruijn, 2012). The use of automaticity-as-habit has been argued to be problematic as, according to Wood \& Rünger (2016), automaticity and habit are two distinct constructs. While automaticity may be one characteristic of habit, other non-habitual, implicit processes (e.g., classical conditioning and non-associative learning) are also partially characterised by automaticity. Therefore, to effectively distinguish between habit and other implicit processes, it is suggested that definitions of habit should feature, but not be solely represented by, automaticity (Evans \& Stanovich, 2013; Wood \& Rünger, 2016).

In attempting to address the aforementioned problems Gardner proposed a new definition of habit; "a process by which a stimulus automatically generates an impulse towards action, based on learned stimulus-response associations" (Gardner, 2015, p. 280). Gardner (2015) argued that by defining habit as a process in which an action is cued instead of a behaviour itself, it overcomes the circularity of defining it as both a behaviour and a determinant of behaviour. Furthermore, this definition incorporates the characteristic of automaticity without conceptualising habit as only automaticity. While this definition overcomes previous criticisms in defining habit, it may be possible to refine our understanding and definition of habit further, by drawing on a' common-sense' approach, and 


\section{LAY REPRESENTATIONS OF HABIT}

incorporating the beliefs of lay people. Given that the term of habit is widely used in lay vernacular and popular media, there remains a knowledge gap in understanding how lay people understand and make sense of the term habit and how their understanding aligns with scientific conceptualisations. Investigating lay understandings of illness has helped researchers develop models to assist people to cope with illness (Hagger, Koch, Chatzisarantis, \& Orbell, 2017; Hagger \& Orbell, 2003; Leventhal, Phillips, \& Burns, 2016)and in a similar way, understanding lay representations of habit, may provide clarity on how researchers could better define habit, develop valid measurements of habit, and evaluate habit-based interventions.

Given the lack of consensus around the definition of habit, understanding the best way to measure habit has also provoked much discussion in the literature. Given that some researchers also argue that the experience of a habit lies outside of conscious awareness (i.e. automatic), this probably reduces the reliability of self-report measures as individuals may not be able to accurately self-reflect on a non-conscious experience (Hagger, Rebar, Mullan, Lipp, \& Chatzisarantis, 2015; Sniehotta \& Presseau, 2012). Similarly, depending on the lay representations of habit, their interpretation of any survey questions relating to habit may be different from the intended meaning, which in turn calls into question, the accuracy of habit measurement.

In an exploratory think-aloud study of a popular measure of habit (i.e., the self-report habit index; Verplanken \& Orbell, 2003), the authors found a number of inconsistencies in how individuals interpret the measurement (Gardner \& Tang, 2014). In particular, participants' interpretation of items deviated from the intended meaning of the measurement items (e.g., misinterpreting an item to be measuring memory capacity instead of whether the behaviour can be performed without having to consciously remember it) and problems with participants having difficulties comprehending the meaning of the items (e.g., 


\section{LAY REPRESENTATIONS OF HABIT}

misunderstanding whether the question referred to a generic or context-specific situation). Lay characterisations of habit, therefore, may help to improve measurement items as item wording can better reflect lay language, potentially resulting in reduced misinterpretation.

Similarly, such misinterpretations might affect the way habit interventions are subsequently evaluated. For example, there may be a mismatch between what a participant expects that will change (e.g., a behaviour will always be triggered across setting) compared with what the habit-based intervention is designed to change (e.g., an increase in behavioural automaticity strength that leads to an increase in behaviour after a very specific cue is encountered). Thus, without a sound understanding of lay representations of habit, participants of habit-based interventions may not understand the procedures or the expected changes that could occur. By understanding the lay representations of habit, interventions may increase face validity, become more implementable, and the evaluation of such interventions may be improved (Planas, 2008). One study has explored the experience of habit formation with participants enrolled in a weight loss intervention that was designed using habit-formation principles (Lally, Wardle, \& Gardner, 2011). While participants reported experiences of automaticity development consistent with a scientific characterisation of habit, they also identified issues translating the new habitual behaviours to multiple settings. Participants in the study reported that they typically embedded the new habitual behaviour is an existing routine. In turn, the habitual behaviour did not occur outside of the routine, in other setting (e.g., such as weekends or holidays). By having an understanding of lay representations of habit (e.g., their belief that habitual behaviours will occur in all contexts), clinicians can pre-emptively provide clear expectations (e.g., a habit it a contextbound response) to align the participants experience with the intervention goals

Lay representations of habit may also provide clarity regarding individuals' use of the words 'habit' and 'routine' interchangeably, despite scientific conceptualisations treating 


\section{LAY REPRESENTATIONS OF HABIT}

them as distinct constructs. The overlap between habit and routine appears to be particularly prominent in popular media. For example, a Google search of "health habits" finds endless articles spruiking, for example, the 20 "health habits" that people should adopt (Kylstra, 2014) or one of a hundred books that purport to provide the key to making healthy habits. A number of these articles and books use the word "habit" to mean specific cue-response automatisms (e.g., set a specific time to disconnect from social media every morning) but, more regularly, is used to refer to broader lifestyle behaviours that are likely governed by deliberative, conscious decision making (e.g., "drink more water, in general"; "stop drinking soda"). Despite theorists defining habit and routine as distinct constructs, even throughout the scientific literature and in presentations at scientific meetings, the words 'habit' and 'routine' are often used interchangeably (Clark, 2000), which may reflect that the two constructs are socially constructed to have the same meaning. To date, despite how commonly the words habit and routine are interchangeably used, there is no published research, to the authors' knowledge, that seeks to understand what, if any, differences exist in lay representations of habit compared to a routine. To best understand how lay people characterise habit, it would seem beneficial to explore if or how lay people differentiate these two constructs, which may help to further refine current scientific conceptualisations of habit and, in turn, potentially improve habit measurement and intervention.

\section{Exploring lay representations of habit}

The overarching aim of the current investigation was to explore how lay people represent habit. The research explored how lay people explicitly define habits, the types of behaviours lay people identify as habitual, and how they differentiate 'habit' with the construct 'routine'. The first study used an online, open-ended questionnaire to elicit what lay people believe to be the salient features of habit, and the second study involved a series of interviews and focus groups, to explore individuals representations of habit, including what 


\section{LAY REPRESENTATIONS OF HABIT}

behaviours participants identify as habitual and to what extent (if any) individuals differentiate habit and routine.

\section{Methods}

\section{Participants}

Participants were a convenience sample of adults recruited online through social media, the University broadcast email system, and the School's research pool for the opportunity to receive course credit. Study one involved 158 participants $(79.7 \%$ female, aged between 17 and 75) and study 2 comprised of 10 participants interviewed individually, and 17 participants who were interviewed in seven focus groups (64.0\% female and similarly aged between 18 and 65). No incentives or compensation were provided to participants. Sample demographic characteristics are displayed in Table 1. No participants who consented to be a part of the study later dropped out.

\section{Design and Procedure}

The current investigation adopted an interpretivist approach to understanding lay (i.e., non-experts) representations of habit (Green \& Thorogood, 2018). The Consolidated Criteria for Reporting Qualitative Research (COREQ) checklist (Tong, Sainsbury, \& Craig, 2007) and the APA Journal Article Reporting Standards for qualitative research (JARS-Qual; American Psychological Association, 2019), guided the reporting of the research. Approval for study procedures was granted prior to data collection from the Institution Human Research Ethics Committee. Study 1 data was collected at one time-point, online, and presented using Qualtrics $^{\mathrm{TM}}$, an online survey tool. Participants were asked "how would you describe a habit" and were provided an open, multi-line, text entry box with the stem "a habit is...". One, broad, open-ended question was used to understand the initial, most salient response of 


\section{LAY REPRESENTATIONS OF HABIT}

participants which would likely include important or prominent features of habit (Reja, Manfreda, Hlebec, \& Vehovar, 2003).

For Study 2, a semi-structured interview guide was developed using open-ended questions to stimulate and explore participants' representations of habit. It was expected that this approach would produce data that most accurately presented the scope of lay understandings. The interview guide was reviewed by all authors and pilot tested on three participants that informed minor revisions of the guide, improving participant understanding and clarity of questions. The interview guide with suggested probing questions can be found in Appendix A (supplemental materials). Interviews and focus-groups took between 20 minutes and 1 hour with an average length of $30-40$ minutes. An approximate sample size was chosen before recruitment based on previous research (e.g., Hamilton, Peden, Keech, \& Hagger, 2019; Hamilton, Price, Keech, Peden, \& Hagger, 2018) and the authors' previous experience in qualitative methodologies with the expectation that this would be adapted if new data was still being obtained (i.e., before theoretical/data saturation) (Glaser, Strauss, \& Strutzel, 1968; Saunders et al., 2018). Participants chose to be interviewed either over the phone or face-to-face, individually or in small groups at the hosting Institution. All data collected over the phone was in a one-on-one interview format whereas data collected in person was a mix of one-on-one interviews and focus groups. Author $\mathrm{DB}$, a male $\mathrm{PhD}$ candidate and clinically trained psychologist, conducted all interview and focus groups independently (i.e., no-one else was present). All participants were notified that the study was a component of DB's PhD research at the time of the interview. All authors have previously conducted research or written commentaries regarding the role of habit as an automatic process in health behaviours that likely shaped their interpretation of the data generated in the current study. Participants consented to be audio-recorded and later transcribed for dataanalysis. Notes were made during each interview or focus group to aid the interviewer to 


\section{LAY REPRESENTATIONS OF HABIT}

further explore relevant concepts, but these were not used in data-analysis and were not provided to participants (Ortlipp, 2008).

\section{Analytic Strategy}

For both study 1 and study 2 the data was analysed using theoretical thematic content analysis (Braun \& Clarke, 2006, 2013; Joffe \& Yardley, 2003) in Nvivo 12 qualitative analysis software. This method was selected as it is guided by existing theoretical concepts, as well as the researchers' standpoint and disciplinary knowledge. The data were analysed in accordance with the six phases set out by Braun and Clarke (see Braun \& Clarke, 2006, 2013 for a detailed description of the six phases). The theoretical concepts informing the interpretation of the coding were based on the authors' knowledge of the habit literature and from an analysis of the multiple habit definitions featured in the review conducted by Gardner (2015). In reviewing these definitions of habit, the authors of the current investigation found that the definitions had three main themes: habits were typically defined by what it is (e.g., a process, behaviour, tendency, or type of automaticity), by its features (e.g., the automaticity of the impulse or act, stimulated by a stable cue/context, which may be goal independent), and by how it is formed (e.g., via repetition over time and reinforced through rewards). These themes were used in helping the current authors identify and organise the themes that emerged in the analysis of Study 1 and Study 2. Author DB coded the data by first using specific words or phrases used by participants for relevant chunks of data. These initial codes were then amalgamated into relevant themes that both fit with a framework of habit adapted from the Gardner (2015) review and by those which were novel but still relevant. Codes were reviewed with author $\mathrm{KH}$ and inconsistencies resolved via discussion with both authors. The themes were also reviewed, discussed, and refined with author KH. Participants were not provided the opportunity to review or comment on themes. 
LAY REPRESENTATIONS OF HABIT

\section{Results}

\section{Study 1}

Participants described habits in three broad ways (see Figure 1): by what it is (e.g., an explicit outcome or internal mechanism), by habit's features (e.g., it is enacted automatically and repeated), and by how they evaluated habits (e.g., being both "good" and "bad").

Participants' answers provided an important first step to understanding how lay people represent habit and what a lay population perceive as most important.

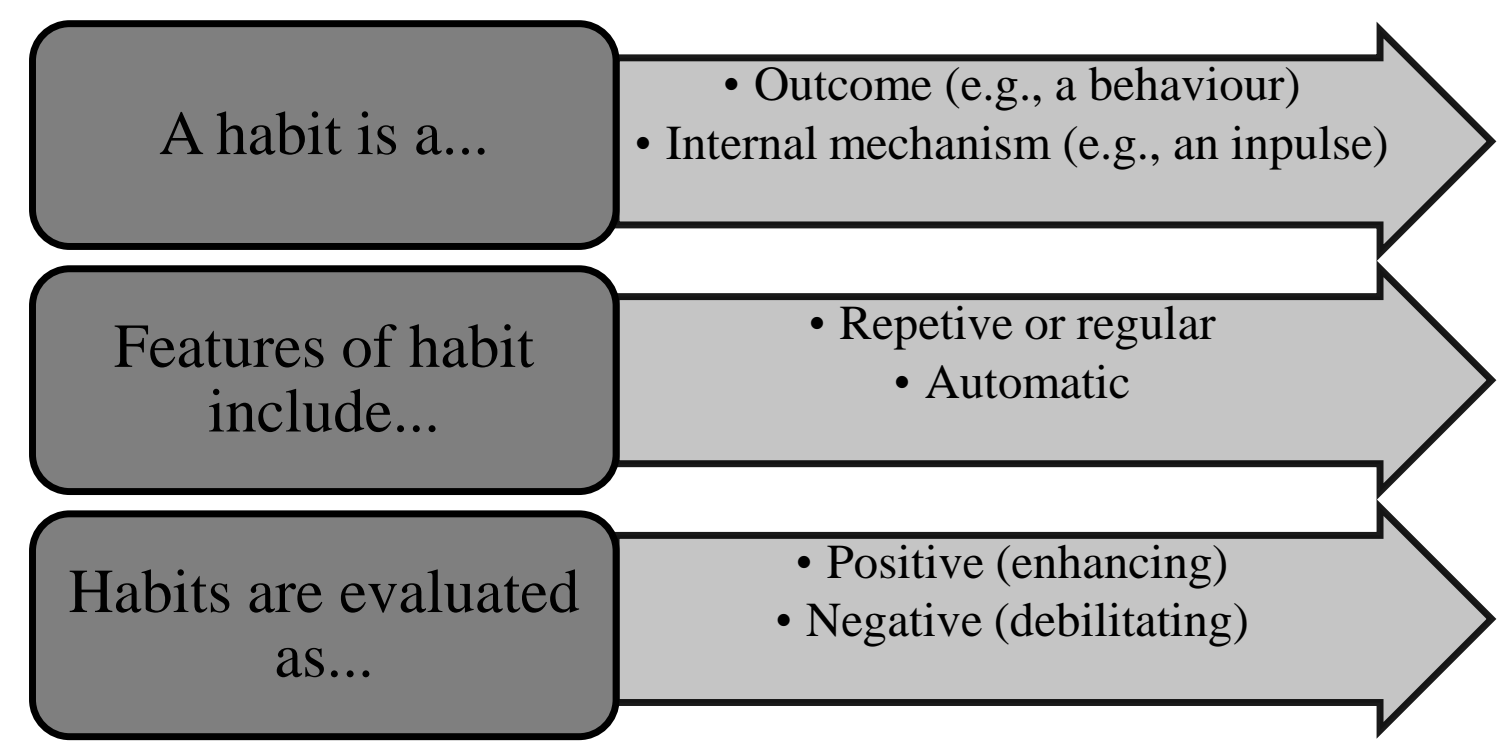

Figure 1. Overview of themes identified in Study 1

What is a habit? The open-ended question began with the stem "a habit is...". This prompted many participants to begin their answer with what they believe the essential property of a habit is (i.e., a behaviour, a process, a pattern etc.). While many participants began their answer with "something that...", 74 participants specifically identified a habit as being an outcome such as a behaviour, an action, or by being some other type of explicit outcome (e.g., a pattern of behaviours, an activity, a thought, a task, a conduct, an emotional reaction, etc.). A smaller number $(\mathrm{n}=14)$ of participants identified that habit is an internal mechanism and not based on any one specific outcome. These participants used phrases such as habit is "... a tendency", “... a practice”, or “...an impulse”. 
LAY REPRESENTATIONS OF HABIT

Features of habit. Two prominent features of habit were identified in the open-ended survey responses. The first, and most common feature was that a habit is repetitive $(\mathrm{n}=122)$. Participants described habits as something that is "repeated", that is engaged with some type of "regularity", is something that is "routinely" enacted, or is done "frequently" ("an action regularly repeated"; "something you do consistently [either daily, weekly etc.]..."; "an ingrained behaviour that you repeat, often..."). Some participants $(n=13)$ also described how habits are "developed over time", which extends on the concept of repetition, as to repeat something is to do it on multiple occasions over a length of time. For example, one participant wrote that a habit is "An unconsciously enacted behaviour...learned through repetition, over time", while another wrote a habit is "something someone does often after a long period of time doing it...”.

Another common feature identified by participants was that habits are defined by their automaticity, with many participants $(\mathrm{n}=85)$ defining habits by this feature. Participants described habits in terms of being "thoughtless", "unconscious", or "automatic". Typically, the respondents used the words "without thought", "unconscious", and "automatic"; however, also described how a habit is "compulsive", "instinctively done", "uncontrolled", and enacted "without knowing". For example, one participant wrote, a habit is... "An action or thought that is repeated 'automatically'; that is, with little conscious thought/attention to it", while another stated a habit is a "recurring pattern of behaviour that is often automatic in nature...". The notion of a habit being enacted automatically can be further inferred when participants described habits as "difficult to stop" $(\mathrm{n}=19)$. If a behaviour is automatically enacted, without awareness, then this is similarly likely to be something that can be hard to control or inhibit; "an impulse which is hard to stop"; “... what you do on regular basis sometimes unconsciously and which is hard to get rid of". 


\section{LAY REPRESENTATIONS OF HABIT}

Evaluation of habit. A small sample of the participants $(n=9)$ specifically provided a subjective evaluation (i.e., whether habits are positive or negative) of habits. All but one of the participants who provided an evaluation specifically described how habits can be both positive or negative. For example, one participant wrote, "Habits can be good (like taking the stairs instead of the lift) or bad (like chewing your fingernails)", while another wrote, "something that you do or practice regularly, which may or may not be beneficial to your health".

\section{Study 2}

In Study 2, while participants were not asked to define habits, they were asked to reflect on their own habitual behaviours. In doing so, they also characterised habit in three broad ways: by the characteristics of behaviours they identified as habits (e.g., simple, discrete behaviours; clustered, repetitive behaviours synonymous with routine; self-identity characteristic), by the features of habit (e.g., automatic; frequent; stable cue / context; and emotionally rewarding), and by how they evaluated habits (e.g., being "good" and consistent with goal; being "bad" and inconsistent with goals). See (see Figure 2).

Furthermore, given individuals often use the word habit and routine interchangeably, participants were also asked to describe if these two constructs are distinct from each other. Three key differences emerged regarding the distinction between habits and routines: routines were identified as multi-step patterns of behaviour compared to the habitual behaviours which were seen as discrete and simple; there was a greater degree of agency with routines; and habits were seen as typically driven by emotions compared to routines. Participant 


\section{LAY REPRESENTATIONS OF HABIT}

responses are summarised below and provide a rich understanding regarding how lay people characterise habit and how they distinguish it from similar constructs.

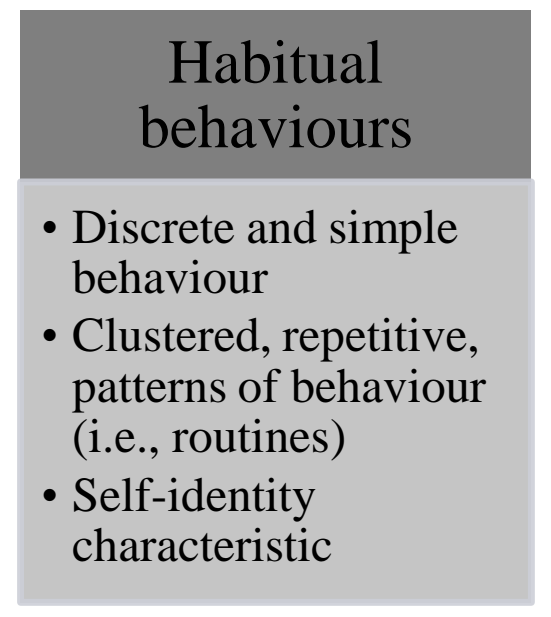

\section{Features of habit}

- Automatic

- Frequent

- Stable cue / context

- Emotionally rewarding / comforting

\section{Evaluation of habit}

- Positive and goal dependent

- Negative and goalindependent

Figure 2. Overview of themes identified in Study 2.

Habitual behaviours. As indicated above, participants were asked to provide examples of habits and habitual behaviours. In analysing the types of behaviours they identified as habitual, three key findings emerged: participants described habits as either a discrete behaviour; clustered, repetitive, patterns of behaviours, synonymous with routines; or participants used habit to represent a characteristic of their identity.

When participants were asked to reflect upon which behaviours they described habits, first as comprising discrete, single-step, behaviours such as "biting my nails", "drinking beer", "having my morning coffee", or "going through my phone. Participants also described clustered, repetitive patterns of behaviours and used the word "routine" interchangeably such as "sleeping habits - the things I do before I go to bed", "my morning routine", and "I have a habit of, what I think is a habit to me, a routine. I must do certain things a certain way". The descriptions participants described for these clustered behaviours often had a latent goal (e.g., getting ready in the morning or going to sleep at night) but were likely made up of many smaller actions, steps, or behaviours. Given the complexity of these latent goals, it appears less likely that the whole process is 'outside of conscious awareness' although they are likely 


\section{LAY REPRESENTATIONS OF HABIT}

to be performed regularly consistent with the lay representation of habit identified in study 1 .

Third, some participants in the focus groups and interviews used the word habit to described personal characteristics that represented part of their identity. For example, one participant described how they 'habitually' used poor grammar while another one identified as a 'dogwalker'. While walking a dog could be a habit by both a scientific and lay definition of habit, the participant did not refer to walking a dog in this way (i.e., a triggered response) but as a characteristic of who they are. Similarly, another participant described a habit of "waking up early because I've been a barista for [many] years" [FG5] while another believed they had a habit of checking their bags before they left home because, as a parent, they needed to be organised. Each of these identity characteristics may or may not include specific habitual behaviours but were described as an representative of them instead of a specific cue-response mechanism.

Features of habit. Consistent with Study 1, in 15 of the interviews and focus groups, participants provided a description of habitual behaviour as being enacted automatically, that is "without thought", or "unconsciously" ("I think habit would be some sort of behaviour that you do without thinking" [interview 8; I8]). Automaticity was seen as a defining difference between habitual behaviours and other non-habitual behaviours when participants were probed to describe when they believed a behaviour had moved into being habitual ("Well I think that if you have to actively remember to do it, and remind yourself to do it, or have someone remind you to do it or you have to think about doing it, that's not really a habit" [focus group 3; FG3]).

More than half of the participants also described habitual behaviour as being repetitive over time. When describing the concept of repetitiveness, participants would describe this as being something that is either synonymous with frequency or regularity ("..cause a habit to me is really like the continuity of action, of doing something over time" 


\section{LAY REPRESENTATIONS OF HABIT}

[I6]; “...a habit is something I would classify I do on a regular basis” [FG1]). The idea of repetitiveness meaning any behaviour that is performed in a patterned way was also highlighted. Participants elaborating that these behaviours are those performed repeatedly at set times/days every day, week, or month ("the things that I do constantly every day, every week, every month, whatever, those sorts of things [are habitual]" [FG4].

In 10 of the interviews and focus groups, participants described an important feature of habit is that they are evident in the presence of a stable cue or context. When describing their habitual computer-gaming, one participant described the consistency of the context by stating "If I come home [I] game at a particular hour. I pretty much do it roughly around the same time for roughly around the same amount of time that I'm playing” [FG5]. Similarly, when a participant reflected on brushing their teeth, they reported "I'll always brush it after breakfast, in the morning. I always brush it last thing before I go to bed, so I don't eat anything before going to bed." [I8]. Similarly, some participants described how particular cues trigger a habitual response (“...it's like a behaviour that's usually triggered by an emotional response, but sometimes it's a hidden emotion" [FG3]; "I say it's a habit... because it stems from a stimulus... so it's like, for example, with the nail biting over a stressful situation, the habit is to bite my nails because it's what I always do" [I7]). Other participants described the cue-response or triggered feature of habits by describing how habitual behaviours can be performed within a routine (i.e., one behaviour is the trigger for the next behaviour in the sequence). For example, one participant stated "[there are] habits of just brushing your teeth, eating breakfast, having a coffee, I think that's just something that's related to routine that you just do it automatically every day" [I5].

Habits being described as emotionally rewarding or comforting was identified in 9 of the interviews and focus groups. These individuals suggested that a habit is often formed and maintained because it serves a function such as an emotional regulation strategy (e.g., biting 


\section{LAY REPRESENTATIONS OF HABIT}

nails when feeling anxious; "habits... are soothing or comforting or reassuring, things that you go to without thinking to... put you in a better state maybe" [I1].

Evaluation of habit. As with study 1, some participants described both positive and negative evaluations to habitual behaviours. Some of the participants in the interviews and focus groups went further and described how the "positive" habits were typically consistent with goals, while the "negative" habits were goal-independent (i.e., were inconsistent with goals or desires). For example, one participant reflected specifically on forming a nutritionbased habit to promote the health of their family (“... we weren't eating very good, so we've tried to make it a habit of blending vegetables in a drink [in the morning], and I think now whenever I don't have that in the morning it feels wrong" [FG7]. Another participant reflected how they believed that it is often the emotionally cued habits that are "bad" and therefore goal-independent ("I think there's two different types of habits. First there's the emotional response ones, but there's also the ones that you work towards becoming an automatic thing that you just do at that point in time, or after something. It just becomes something that you work towards not thinking needing to do about it" [FG3].

A habit or routine? Everyday language use of the word habit is, at times, used synonymously with the word routine (Clark, 2000; Kylstra, 2014). To further explore the distinct representations of habit, by lay people, participants were asked to describe what were, if any, the differences between a habit/habitual behaviour and a routine. Three key differences emerged: routines are multi-step patterns of behaviour compared to the habitual behaviours which are discrete and simple; there is a higher level of agency with routines; and habits are typically driven by emotions as opposed to being simply a routine.

In 13 of the interviews and focus groups, participants identified that they would distinguish a routine from a habit by the complexity of the behaviour. Routines were 


\section{LAY REPRESENTATIONS OF HABIT}

described as typically involving multiple steps or patterns of behaviours. For example, one participant stated "I think the difference between habits and routines is that habits are singular, whereas routines are multiple things strung together" [I7], and another participant reported, "[my] morning routine is my habit of meditating and getting up and making my child's bottle and then brushing my teeth. Those are daily habits that I have that are in my routine" [I8].

In 16 of the interviews and focus groups, participants described how routines are enacted with a greater sense of agency and awareness. They described how there is a degree of flexibility and control in routines and, while they can be performed mindlessly, they can choose to complete the pattern of behaviours in a different sequence. One participant described the agency and choice of routines, "My bedtime routine would be I do my physio and then I have a shower and go to bed. But, some nights I might not have a shower because I'm too tired or I had a shower in the morning or whatever" [FG9]. Another participant described how they believed that most people likely complete their routines in the same order; however, could choose to change it easier than with habits ("There is more flexibility with routines when event though most people don't think about them, you could, whereas habit is more automatic than that" [I8]).

When participants described their own routines to provide an illustration to their answers, they would always be in the context of an overarching goal (e.g., getting ready for work in the morning or getting prepared for bed at night). Participants contrasted this with examples of habitual behaviours which, they believed, could also be driven by an emotional need or function (e.g., biting nails in response to anxiety or eating junk food in response to boredom) whereas routines rarely were (“A habit like I bite my nails or whatever, it's very...you get some gratification out of it or something like that. It's a stronger feeling" 


\section{LAY REPRESENTATIONS OF HABIT}

[FG4]; [a routine] is based on necessity like, you've to take your kids to school, you've got to go to work. Whereas habits are more...it's the behaviour you fall back into" [FG7]).

\section{Discussion}

Scientific definitions of habit include both consistent and contradictory features that impact on the way habit is measured, modelled, and intervened upon. To date, such definitions have often ignored how lay people represent habit. In this chapter we propose that an understanding of lay representations may help better refine current scientific conceptualisations and measurement of habit as well as improve lay expectations and evaluations of habit-based interventions. The overarching aim of the research was to explore how lay people represent habits. Study 1 used an online open-ended questionnaire to elicit what lay people believe to be the salient features of habit. Study 2, in a series of interviews and focus groups, further investigated how lay people represent habit by exploring what lay people identify as habitual behaviour, the features of habit, and how lay people differentiate habit from the similar concept of routine.

The findings showed that similarly to scientific conceptualisations of habit, some lay people described habit is a psychological process, such as an impulse, whereas many people described habit as a type of outcome, such as a behaviour. Believing that an outcome, such as a behaviour, itself is a habit might be problematic. If lay-people believe that there is something inherent about a behaviour that makes it a habit, it may lead to inaccurate expectations when forming habits. For example, given lay people believe that habits are automatic and occur outside of conscious awareness, they may believe that they will always perform the behaviour, across settings and contexts instead of being triggered by a specific cue or set of cues. This belief could explain why participants in a weight-loss intervention program struggled to program effective cues to repeat their weight-loss behaviours and failed 


\section{LAY REPRESENTATIONS OF HABIT}

to repeat their behaviours in other contexts such as on weekends or on holiday (Lally et al.,

2011) as they did not pair a cue that could occur across contexts.

When asked to describe habits, participants described a broad array of behaviours. For example, participants discussed discrete behaviours (e.g., biting nails) but similarly discussed clustered, repetitive, patterns of behaviour that are synonymous with routines (e.g., having a coffee, brushing teeth, showering, all in the morning) The clustered patterns of behaviours are likely governed by both automatic and reflective processes, particularly given they are, by definition, multi-step and complex behaviours (Mullan \& Novoradovskaya, 2018). For example, an individual might habitually start the shower after they have brushed their teeth, but likely need to have some conscious reflection to ensure the water is at the right temperature and they wash their body and hair thoroughly (Gardner, Phillips, \& Judah, 2016; Phillips, 2019). Yet, contrary to the idea of habits being multi-step, when participants were asked to identify what, if anything, differentiated habits from routines, they described routines as multi-step and complex patterns of behaviours and habits as typically simple and discrete behaviours. Furthermore, participants described how they had more control of routines. For example, while an individual may routinely have coffee, eat toast, brush their teeth, and watch the morning news, they could also choose to change the order, or have a tea instead of a coffee. Thus, when given the opportunity, participants differentiate habits from routines by, in part, the complexity and control involved in them; however, still describe complex routines as habit in their everyday language use.

Furthermore, some participants used the word habit to denote personal characteristics such as being "a dog-walker". To describe habit in a way that it represents a part of one's self-identity (i.e., dog walker) was a concept integrated into the development of the selfreport habit index (SRHI), a widely used measure of habit (Verplanken \& Orbell, 2003). Verplanken and Orbell (2003) believed that habits were a part of how people organise their 


\section{LAY REPRESENTATIONS OF HABIT}

everyday life and, therefore, likely reflect part of an individual's self-identity. However, if the concept of habit is used to denote personal characteristics, it would lead to a large variety of actions to be classified as a habit that are likely outside of both the lay and scientific definition of habit (i.e., a cued, automatic response), reducing the specificity of the concept of habit. For example, one participant described themselves as having a habit of using poor grammar, which is unlikely to be an automatic cued response but more so representative of errors in their use of grammar that they frequently do. Taken together, it seems lay people believe habits to be a type of behaviour. When using the word habit or describing habitual behaviours, lay people describe a wide variety of behaviours from single-step, simplistic behaviours (e.g., brushing teeth after waking); to grouped, clustered, patterns of behaviours (e.g., healthy eating patterns); or behaviours that are typical of them and represent a part of their identity (e.g., a morning smoothie drinker).

This research also elicited how lay people characterise habits by, in part, exploring the features of habit. Across both Study 1 and Study 2, results showed some consistent descriptions of the features of habit. Specifically, lay people characterise habit as automatic and frequent or regular. The feature of automaticity was identified through participants describing habits as being outside of conscious awareness and enacted without thought. This is consistent with scientific definitions of habit that define habit as something which is elicited automatically. This knowledge is useful as the behavioural automaticity sub-scale of the SRHI (i.e., the self-report behavioural automaticity index [SRBAI]; Gardner, Abraham, et al., 2012), that focuses on the automatic component of habit, is widely used in the scientific literature as a proxy for habitual behaviour. Habit interventions that seek to intervene upon and increase behavioural automaticity will likely be consistent with what lay people expect to change within that intervention. For example, if an individual engages in a habit-intervention to increase fruit consumption, focusing on increasing the behavioural automaticity of fruit 


\section{LAY REPRESENTATIONS OF HABIT}

consumption will likely be consistent with what the participant expects to change from the intervention (de Bruijn, Gardner, van Osch, \& Sniehotta, 2014; Orbell \& Verplanken, 2010).

Participants also described the feature of frequency and regularity. While these two features are suggested to be distinct constructs in the scientific literature (i.e., "frequency" refers to something that happens often while "regularly" refers to something that happens in a constant or definite pattern; Merriam-Webster, 2019), they may actually be socially constructed by lay people to mean the same thing (e.g., an individual will brush their teeth frequently and regularly, every 12 hours). Participants often used the terms interchangeably, thereby making it difficult to identify whether habits are characterised by lay people as being one or both features. However, given some participants also described habit as occurring in a patterned way (e.g., occurring weekly or monthly), it is likely that both constructs form part of how lay people characterise habit. Furthermore, the concept of "frequency", "regularity", or "in a patterned way" was most often expressed in reference to time (e.g., a habit is regular if it occurs at the same time of week or time of day). This may be problematic given a scientific representation of habit suggests that once formed, a habit does not have to occur often (i.e., frequently), but should occur regularly if appropriately cued. Lay people may be misinterpreting the time-based regularity of some habitual behaviours as meaning that habits are, by their nature, consistently repetitive in a pattered way.

According to scientific definitions of habit, it is likely that some habits merely have time-based cues (Gardner, 2015; Orbell \& Verplanken, 2010; Pimm et al., 2016). Thus, habits do not have to occur in a patterned way, the habit may simply be elicited regularly because the individual is exposed to a cue in a patterned way. For example, a person may eat a snack at 5 p.m. every day at work; therefore, the individual may believe they have an "eating a snack at 5 p.m." habit. However, it may be that the person happens to walk past a vending machine when they finish work at 5 p.m. each day and would similarly eat a snack at 


\section{LAY REPRESENTATIONS OF HABIT}

any other point during the day if they also walked past the same vending machine. Other research has similarly found that lay participants struggle to accurately identify the determinants or cues to their behaviour. For example, when asked to identity what triggered previous experiences of smoking or emotional eating, participants of two studies identified negative affect as a cue despite the researchers not finding affect associated with these behaviours (Adriaanse, Prinsen, de Witt Huberts, de Ridder, \& Evers, 2016; Shiffman et al., 1997). Some participants did, however, identify that habits also occurred via different types of stable contexts or cues, including time, place, or mood. This is consistent with other research that has shown that different types of cues predict habit strength and behavioural frequency (Murphy, Eustace, Sarma, \& Molloy, 2018; Pimm et al., 2016). This, again, has important implications for habit-based interventions as some participants may expect that the formation of their habit guarantees behavioural performance at the same time every day, week, month, or year, when this expectation may differ with the researcher or clinician. Results indicate, therefore, that lay people characterise a habit as occurring often (i.e., frequently), in a patterned way (i.e., regularly), and elicited via a context or cue. However, lay people may also be misinterpreting the frequency and regularity of a habit as something inherent about the habit rather than the outcome of frequently or regularly being exposed to the relevant cue.

Finally, some participants described habit as characterised as being emotionally rewarding or comforting. There appeared to be a difference between participants describing mood as a cue for certain habits (e.g., when anxious I bite my nails), and in describing habit as, in and of itself, gratifying to do which, in turn, provokes a feeling of loss if not performed. The experience of comfort evoked from a habit, compared to the experience of a non-habitual behaviour, may be explained by the process of habituation. Habituation is characterised by the decrease in arousal experienced from repeated exposure to a stimulus (Cyr \& Romero, 


\section{LAY REPRESENTATIONS OF HABIT}

2009; Thompson \& Spencer, 1966). The process of habituation is purposefully used in exposure therapy for anxiety disorders, whereby patients are repeatedly exposed to feared stimuli to reduce their fear arousal in the stimuli's presence (Cooper, Clifton, \& Feeny, 2017; Peterman, Carper, \& Kendall, 2019). However, a version of this process may similarly apply to everyday habitual behaviours, promoting the feeling of familiarity when performing the habitual behaviour and provoking a stress-response if not performed. This is also consistent with research investigating lay representations of illness (Goodman, Morrissey, Graham, \& Bossingham, 2005; Hagger \& Orbell, 2003; Platt, Green, Jayasinghe, \& Morrissey, 2014). The common-sense model of illness-representations (Leventhal, Nerenz, \& Steele, 1984) proposes that people select coping strategies based on their cognitive or emotional representations of the illness. Similarly, self-regulatory behaviours (such as biting nails) may be repetitively engaged in, thus forming a habit, because of the beliefs held by lay people of the behaviour's capacity to self-regulate. This emotional experience is not typically included in scientific representations or definitions of habit (Gardner, 2015) and may be an important consideration for future conceptualisations of habit. Participants identified that this feature of habit was also what differentiated it from a routine. Participants described that the feeling of gratification was most likely induced from performing a habit compared to routines, which were more likely to be performed out of necessity or pragmatism. Despite this feature not being included in many definitions of habit, the SRHI includes an item that asks participants if they would "feel weird" if they did not engage in the behaviour (Verplanken \& Orbell, 2003), although this item may not fully capture the emotional component being described by lay people as being a feature of habit. Affect and mood was, therefore, believed to both cue a habit and be evoked by performing or inhibiting a habit.

The emotional effect of some habits was also linked with some participants' evaluations of habit, with some participants describing habit as both positive and negative. 


\section{LAY REPRESENTATIONS OF HABIT}

Participants described that the "bad" or "unhealthy" habits were difficult to inhibit because they felt comforted. Similarly, however, participants described this as a positive experience for the "healthy" or "good" habits. Nearly all participants who choose to provide an evaluation of habit described how they could be both positive and negative. Drawing from the other features that participants characterised as part of habit, participants liked the idea that healthy behaviours could be enacted without thought and frequently. This belief could be used by clinicians to help promote habit-based interventions for healthy behaviours.

However, it may also be useful to deconstruct the idea that a habit is either "good" or "bad". Given participants also believed that habits represented part of their identity, the promotion of the good/bad binary may be internalised to mean that the individual is inherently good or bad based on their habits. While some habitual behaviours may be physically unhealthy (e.g., eating chocolate), if this is done in response to stress, it may also be helping to emotionally regulate the individual (Evers, Dingemans, Junghans, \& Boevé, 2018; Leehr et al., 2015). Demonising the habit, and in turn the individual, as "bad" is likely to be unhelpful given it may have a functional purpose (e.g., to emotionally regulate) (Stephens et al., 2018). Promoting a more neutral valence about habits (i.e., they are neither inherently good or bad but merely an automatic response to a cue) may increase an individual's perceived behavioural control and, in turn, help they change their unhealthy habitual behaviours (Sheeran et al., 2016).

\section{Strengths, Limitations, and Future Directions}

Prior research has used a variety of scientific conceptualisations of habit to inform habit measurement and interventions. The current investigation, however, used a qualitative methodology across two studies to draw upon the beliefs lay people hold regarding how they represent habit, thus filling an important knowledge gap. By exploring how lay people subjectively construct their representation of habit, it provides insight into the similarities and 


\section{LAY REPRESENTATIONS OF HABIT}

contradictions compared to a scientific characterisation of habit, which may lead to inaccuracies in how research participants and individuals interpret measures of habit and their expectations in habit-based interventions. A strength of the current investigation is that it is one of the first, to the authors' knowledge, to qualitatively explore how the concept of habit is represented by lay people. Further, it used two studies to triangulate findings on the defining features of habit that lay people hold, with a good spread of demographic factors on age and education levels, increasing the validity and generalisability of the findings.

The findings from this study should however be considered cautiously, in light of some limitations. Most participants were female and Caucasian, reducing the generalisability of the findings. Future research could explore how other representative populations similarly characterise habits, perhaps in specific contexts such as habits at work or habits in the home. Further, while every effort was made to ensure participants in the interviews and focus groups understood there were no right or wrong answers, there may have been something inherently leading in some questions, such as asking about what, if any, differences existed between habit and routines. This question may have led participants to believe that they needed to identify differences even if they did not necessarily believe that there were any differences between habits and routines. While broader open-ended questions may eliminate this limitation, broad questions can sometimes miss the specificity necessary required in asking direct questions (Reja et al., 2003). Also, while this research focused on what a habit is, it did not explore other important beliefs that lay people may hold about habit, such as how they form and break habits. Future research should, therefore, investigate how lay people form a goal-directed habit or how they attempt to break unwanted habitual behaviours.

\section{Conclusion}




\section{LAY REPRESENTATIONS OF HABIT}

There are a number of scientific conceptualisations of habit that underpin habit measurement and interventions. Despite this, exploring and understanding lay representations of habit has received little attention. This knowledge is important as it can help to identify consistent and/or contradictory beliefs that may further inform scientific discourse, measures, and interventions on habit. The current investigation aimed to fill this knowledge gap by exploring lay representations of habits via two studies. The results of the studies found that lay people hold many similar beliefs regarding habit that are largely consistent with scientific conceptualisations (e.g., habits are triggered automatically by a cue or in a specific context and occur frequently). However, the results also revealed that while participants believed habits were, at times, cued, they struggled to identify time-based cues and they may be confusing time-based cues with the belief that some habits are inherently automatic. The results also found that some lay people believed that habits are linked with emotional regulation. As per the ill-representation literature, this may suggest that some habits are formed because of the beliefs that they aid in emotional regulation. Finally, despite participants differentiating a habit from a routine via the complexity of the behaviour (i.e., a habit is simple/discrete, and a routine is complex and multi-step), they often called routinised patterns of behaviours a habit. Similarly, participants described behaviours as a habit when they represented a personal characteristic or aspect of their identity. While this research is one of the first to explore how lay people characterise the concept of habit, further research is needed to understand how this can be integrated into habit measurement and interventions, as well as how lay people form and break habits. 
LAY REPRESENTATIONS OF HABIT

\section{References}

Adriaanse, M. A., Kroese, F. M., Gillebaart, M., \& De Ridder, D. T. (2014). Effortless inhibition: Habit mediates the relation between self-control and unhealthy snack consumption. Frontiers in Psychology, 5, 444.

Allom, V., Mullan, B. A., Monds, L., Orbell, S., Hamilton, K., Rebar, A. L., \& Hagger, M. S. (2018). Reflective and impulsive processes underlying saving behavior and the additional roles of self-control and habit. Journal of Neuroscience, Psychology, and Economics, 11(3), 135.

American Psychological Association. (2019). Retrieved from Journal Reporting Standards - Qualitative Research website: https://apastyle.apa.org/jars/qualitative

Barandiaran, X. E., \& Di Paolo, E. A. (2014). A genealogical map of the concept of habit. Frontiers in Human Neuroscience, 8. https://doi.org/10.3389/fnhum.2014.00522

Braun, V., \& Clarke, V. (2006). Using thematic analysis in psychology. Qualitative Research in Psychology, 3(2), 77-101. https://doi.org/10.1191/1478088706qp063oa

Braun, V., \& Clarke, V. (2013). Successful qualitative research: A practical guide for beginners. London, UK: SAGE Publications.

Brown, D. J., Hagger, M. S., \& Hamilton, K. (2019). The Mediating Role of Reasoned-Action and Automatic Processes from Past-to-Future Behavior. Retrieved from psyarxiv.com/qrm5b

Clark, F. A. (2000). The concepts of habit and routine: A preliminary theoretical synthesis. The Occupational Therapy Journal of Research, 20(1_suppl), 123S-137S. 
LAY REPRESENTATIONS OF HABIT

Cooper, A. A., Clifton, E. G., \& Feeny, N. C. (2017). An empirical review of potential mediators and mechanisms of prolonged exposure therapy. Clinical Psychology Review, 56, 106-121.

Cyr, N. E., \& Romero, L. M. (2009). Identifying hormonal habituation in field studies of stress. General and Comparative Endocrinology, 161(3), 295-303.

de Bruijn, G.-J., Gardner, B., van Osch, L., \& Sniehotta, F. F. (2014). Predicting Automaticity in Exercise Behaviour: The Role of Perceived Behavioural Control, Affect, Intention, Action Planning, and Behaviour. International Journal of Behavioral Medicine, 21(5), 767-774. https://doi.org/10.1007/s12529-013-9348-4

Evans, Jonathan. S. B., \& Stanovich, K. E. (2013). Dual-process theories of higher cognition: Advancing the debate. Perspectives on Psychological Science, 8(3), 223-241.

Evers, C., Dingemans, A., Junghans, A. F., \& Boevé, A. (2018). Feeling bad or feeling good, does emotion affect your consumption of food? A meta-analysis of the experimental evidence. Neuroscience \& Biobehavioral Reviews, 92, 195-208.

Gardner, B. (2015). A review and analysis of the use of 'habit' in understanding, predicting and influencing health-related behaviour. Health Psychology Review, 9(3), 277295. https://doi.org/10.1080/17437199.2013.876238

Gardner, B., Abraham, C., Lally, P., \& de Bruijn, G.-J. (2012). Towards parsimony in habit measurement: Testing the convergent and predictive validity of an automaticity subscale of the Self-Report Habit Index. International Journal of Behavioral Nutrition and Physical Activity, 9(1), 102. https://doi.org/10.1186/1479-5868-9-102 
LAY REPRESENTATIONS OF HABIT

Gardner, B., de Bruijn, G., \& Lally, P. (2012). Habit, identity, and repetitive action: A prospective study of binge-drinking in UK students. British Journal of Health Psychology, $17(3), 565-581$.

Gardner, B., Phillips, L. A., \& Judah, G. (2016). Habitual instigation and habitual execution: Definition, measurement, and effects on behaviour frequency. British Journal of Health Psychology, 21(3), 613-630.

Gardner, B., \& Tang, V. (2014). Reflecting on non-reflective action: An exploratory think-aloud study of self-report habit measures. British Journal of Health Psychology, 19(2), 258-273. https://doi.org/10.1111/bjhp.12060

Glaser, B. G., Strauss, A. L., \& Strutzel, E. (1968). The discovery of grounded theory; strategies for qualitative research. Nursing Research, 17(4), 364.

Green, J., \& Thorogood, N. (2018). Qualitative methods for health research. Sage.

Hagger, M. S., Rebar, A. L., Mullan, B., Lipp, O. V., \& Chatzisarantis, N. L. D. (2015). The subjective experience of habit captured by self-report indexes may lead to inaccuracies in the measurement of habitual action. Health Psychology Review, 9(3), 296302. https://doi.org/10.1080/17437199.2014.959728

Hagger, M. S., Trost, N., Keech, J. J., Chan, D. K. C., \& Hamilton, K. (2017). Predicting sugar consumption: Application of an integrated dual-process, dual-phase model. Appetite, 116, 147-156. https://doi.org/10.1016/j.appet.2017.04.032

Joffe, H., \& Yardley, L. (2003). Content and thematic analysis. In D. F. Marks \& L. Yardley (Eds.), Research Methods for Clinical and Health Psychology (pp. 56-68). SAGE Publications. 


\section{LAY REPRESENTATIONS OF HABIT}

Kylstra, C. (2014). 20 Healthy Habits You Should Adopt In Your Twenties. Retrieved November 14, 2019, from Buzzfeed website:

https://www.buzzfeed.com/carolynkylstra/healthy-living-habits

Lally, P., Wardle, J., \& Gardner, B. (2011). Experiences of habit formation: A qualitative study. Psychology, Health \& Medicine, 16(4), 484-489.

https://doi.org/10.1080/13548506.2011.555774

Leehr, E. J., Krohmer, K., Schag, K., Dresler, T., Zipfel, S., \& Giel, K. E. (2015). Emotion regulation model in binge eating disorder and obesity-a systematic review. Neuroscience \& Biobehavioral Reviews, 49, 125-134.

Maddux, J. E. (1997). Habit, health, and happiness. Journal of Sport and Exercise Psychology, 19(4), 331-346.

Mullan, B., \& Novoradovskaya, E. (2018). Habit mechanisms and behavioural complexity. In The Psychology of Habit (pp. 71-90). Springer.

Murphy, J., Eustace, N., Sarma, K. M., \& Molloy, G. J. (2018). Habit strength and adherence to oral contraceptives: The role of time-and place-based cues. International Journal of Behavioral Medicine, 25(4), 431-437.

Nilsen, P., Roback, K., Broström, A., \& Ellström, P.-E. (2012). Creatures of habit: Accounting for the role of habit in implementation research on clinical behaviour change. Implementation Science, 7(1), 53.

Orbell, S., \& Verplanken, B. (2010). The automatic component of habit in health behavior: Habit as cue-contingent automaticity. Health Psychology, 29(4), 374-383. https://doi.org/10.1037/a0019596 
LAY REPRESENTATIONS OF HABIT

Orbell, S., \& Verplanken, B. (2015). The strength of habit. Health Psychology

Review, 9(3), 311-317. https://doi.org/10.1080/17437199.2014.992031

Ortlipp, M. (2008). Keeping and using reflective journals in the qualitative research process. The Qualitative Report, 13(4), 695-705.

Ouellette, J. A., \& Wood, W. (1998). Habit and Intention in Everyday Life: The Multiple Processes by Which Past Behavior Predicts Future Behavior. 124, 54-74.

Peterman, J. S., Carper, M. M., \& Kendall, P. C. (2019). Testing the habituationbased model of exposures for child and adolescent anxiety. Journal of Clinical Child \& Adolescent Psychology, 48(sup1), S34-S44.

Phillips, L. A. (2019). Challenging assumptions about habit: A response to Hagger (2019). Psychology of Sport and Exercise.

Pimm, R., Vandelanotte, C., Rhodes, R. E., Short, C., Duncan, M. J., \& Rebar, A. L. (2016). Cue consistency associated with physical activity automaticity and behavior. Behavioral Medicine, 42(4), 248-253.

Planas, L. G. (2008). Intervention design, implementation, and evaluation. American Journal of Health-System Pharmacy, 65(19), 1854-1863.

Reja, U., Manfreda, K. L., Hlebec, V., \& Vehovar, V. (2003). Open-ended vs. Closeended questions in web questionnaires. Developments in Applied Statistics, 19(1), 159-177.

Saunders, B., Sim, J., Kingstone, T., Baker, S., Waterfield, J., Bartlam, B., ... Jinks, C. (2018). Saturation in qualitative research: Exploring its conceptualization and operationalization. Quality \& Quantity, 52(4), 1893-1907. 
LAY REPRESENTATIONS OF HABIT

Sheeran, P., Maki, A., Montanaro, E., Avishai-Yitshak, A., Bryan, A., Klein, W. M., ... Rothman, A. J. (2016). The impact of changing attitudes, norms, and self-efficacy on health-related intentions and behavior: A meta-analysis. Health Psychology, 35(11), 1178.

Sniehotta, F. F., \& Presseau, J. (2012). The habitual use of the self-report habit index. Annals of Behavioral Medicine, 43(1), 139-140.

Stephens, L. D., Crawford, D., Thornton, L., Olstad, D. L., Morgan, P. J., van Lenthe, F. J., \& Ball, K. (2018). A qualitative study of the drivers of socioeconomic inequalities in men's eating behaviours. BMC Public Health, 18(1), 1257.

Thompson, R. F., \& Spencer, W. A. (1966). Habituation: A model phenomenon for the study of neuronal substrates of behavior. Psychological Review, 73(1), 16.

Tong, A., Sainsbury, P., \& Craig, J. (2007). Consolidated criteria for reporting qualitative research (COREQ): A 32-item checklist for interviews and focus groups. International Journal for Quality in Health Care, 19(6), 349-357.

Triandis, H. C. (1977). Interpersonal behavior. Brooks/Cole Pub. Co.

Verplanken, B., \& Orbell, S. (2003). Reflections on past behavior: A self-report index of habit strength. Journal of Applied Social Psychology, 33(6), 1313-1330.

Verplanken, B., \& Wood, W. (2006). Interventions to Break and Create Consumer Habits. Journal of Public Policy \& Marketing, 25(1,), 90-103.

Wood, W., \& Neal, D. T. (2009). The habitual consumer. Journal of Consumer Psychology, 19(4), 579-592.

Wood, W., Quinn, J. M., \& Kashy, D. A. (2002). Habits in everyday life: Thought, emotion, and action. Journal of Personality and Social Psychology, 83(6), 1281. 


\section{LAY REPRESENTATIONS OF HABIT}

Wood, W., \& Rünger, D. (2016). Psychology of habit. Annual Review of Psychology, 67, 289-314. 
LAY REPRESENTATIONS OF HABIT

Table 1. Sample Demographic Characteristics of Participants in the Study 1 Survey and Study 2 Interviews and Focus Groups

\begin{tabular}{lll}
\hline Variable & Survey & In-person \\
\hline Participants, $N$ & 158 & $25^{*}$ \\
Age, M years (SD) & $30.47(13.90)$ & $29.96(11.70)$ \\
Gender (\%): & & \\
Male & 19.60 & 33.30 \\
Female & 79.70 & 64.00 \\
Other identified/non-disclosed & 0.60 & 4.00 \\
High education level (\%): & & \\
Junior/senior school & 36.10 & 20.00 \\
TAFE/Diploma & 12.70 & 48.00 \\
Undergraduate degree & 22.80 & 16.00 \\
Postgraduate degree & 28.50 & 8.00 \\
Non-disclosed/missing & 0.00 & 8.00 \\
Ethnicity (\%): & & \\
Caucasian & 79.70 & 80.00 \\
Other & 19.00 & 20.00 \\
Non-disclosed/missing & 1.30 & 0.00 \\
\hline *Tw & & \\
\hline
\end{tabular}

*Two participants chose not to answer the demographic questionnaire 